\title{
Study of clinico-haematological profile in dengue fever - A prospective study
}

\author{
K Naveen ${ }^{1 *}$, R S Shankarappa ${ }^{2}$, S Vathsala ${ }^{3}$

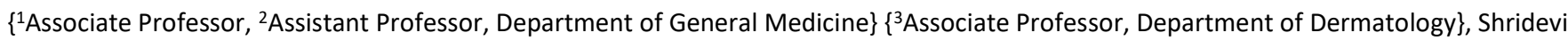 \\ Institute Of Medical Sciences And Research Hospital, Tumakuru, Karnataka, INDIA. \\ Email: drnaveen26@gmail.com
}

\begin{abstract}
Background: Dengue fever with its severe clinical manifestations as dengue haemorrhagic fever and dengue shock syndrome has emerged as a major health problem of international concern. We commonly see patients referred in view of dengue serology positive without warning signs and non severe dengue. Hence the present study is planned to study various clinical manifestations of dengue and analyse the haematological parameters of the same. Methodology: This is an observational study and conducted prospectively total of 100 cases with fever and dengue serology positive were studied. Results: In our study, bradycardia documented in $39 \%$ of cases, leucopenia seen in $53 \%$ of cases, thrombocytopenia of less than 1 lakh is found in $74 \%$ of patients, Haematocrit of less than 40 found in $44 \%$ of patients, dengue fever diagnosed in $69 \%$ of cases followed by dengue haemorrhagic fever diagnosed in $23 \%$ and dengue shock syndrome in $8 \%$ of cases. Conclusion: Majority of cases are still DF, requires only supportive management and not requiring platelet transfusion. So most of the cases should be managed at the local hospital without referring, to reduce cost burden on patients. Early recognition of warning signs and meticulous management reduce the morbidity and mortality of dengue.
\end{abstract}

Key Word: dengue fever.

*Address for Correspondence:

Dr Naveen k, House no 168, Near Adarsha Nursing Home, Sharadha Devi Nagar, Tumkur, Karnataka 572102 INDIA.

Email: drnaveen26@gmail.com

Received Date: 12/03/2020 Revised Date: 24/05/2020 Accepted Date: 10/06/2020

DOI: https://doi.org/10.26611/10211513

This work is licensed under a Creative Commons Attribution-NonCommercial 4.0 International License. (cc)) EY-NC

\begin{tabular}{|l|l|}
\hline \multicolumn{2}{|c|}{ Access this article online } \\
\hline Quick Response Code: & Website: \\
\hline & www.medpulse.in \\
& \\
\hline
\end{tabular}

\section{INTRODUCTION}

The origin of word dengue is derived from the Swahili phrase "Ka-dingapepo" meaning "cramp like seizure caused by an evil spirit". The Swahili word "dinga" may possibly have origin in the Spanish word "dengue". Dengue made its debut as early as 1780 , when Benjamin Rush described the condition as "break bone fever". Dengue fever (DF) with its severe clinical manifestations as dengue haemorrhagic fever(DHF) and dengue shock syndrome (DSS) has emerged as a major health problem of international concern. Dengue is the most extensively spread mosquito borne disease, transmitted by infected mosquitoes of aedes species. Dengue infection in humans results from four serotypes DENV 1 to 4 of Flavivirus genus. With an estimated 50-100 million cases of dengue infection occurs annually in over 100 endemic countries, most cases are reported from Southeast Asia. ${ }^{1}$ India comes under category B of the classification meant for SEAR. Here DHF is an emerging disease with multiple virus serotypes and cyclical epidemics are frequently exist. Although the first recorded outbreak of dengue fever in India was in 1812, evidences of dengue infection was studied only by 1954 , which showed that DEN-1 and DEN-2 were widespread. ${ }^{2}$ The prevention and control of dengue infection in India is carried by National vector borne disease control programme (NVBDCP). As per NVBDCP guidelines, blood samples were collected, to screen for vector borne disease between April 2016 to march 2017 in state of Karnataka. About 34084 blood samples were suspected for dengue and blood samples were collected from 17130 cases, out of them 3453 cases showed positivity for dengue with slide examination rate of $80.8 \%$ and slide positivity rate of $93.3 \%$.Out of population of $28,33,214$ of tumakuru,957 cases were 
suspected of dengue in which 439 tested positive. ${ }^{3}$ Dengue fever is an acute febrile illness and has a wide spectrum of clinical presentations with unpredictable clinical outcome. Majority of patients have self-limiting clinical course and only a small proportion of patients progress to DHF or DSS. This is when they acquire a second infection by a different dengue viral antigen. ${ }^{4}$ Hematopoetic system is the earliest and commonly affected system in Dengue infection with thrombocytopenia being most common laboratory finding. ${ }^{5}$

The mechanism of thrombocytopenia remains unclear in DF. Possible mechanisms may include. ${ }^{6}$

1. Direct bone marrow suppression by the virus

2. Anti-dengue antibody mediated platelet destruction

3. Peripheral consumption of platelets

4. Isolated viral replication in the platelet.

The study findings confirmed that, by using a set of clinical and/or laboratory parameters, one sees a clear-cut difference between patients with severe dengue and those with non-severe dengue.

We commonly see patients being referred in view of dengue serology positive without warning signs and non severe dengue. As this is a tertiary care referral centre with availability of blood products, for few surrounding taluks. Hence the present study is planned to study various clinical manifestations of dengue and to further analyse the haematological parameters of the same. And we found very few studies from this region with detailed description of both clinical and haematological profile in dengue illness. The study of clinic haematological profile in dengue would have a substantial impact on treatment of dengue.

By reducing unnecessary burden on patients

By reducing referals to higher centres

By reducing morbidity and mortality associated with dengue.

Aims and objectives

1. To study the clinical presentations of dengue fever.

2. To study the hematological features of dengue fever.

\section{MATERIALS AND METHODS}

This is an observational study and conducted prospectively for a period of 6 months from August 2019 to January 2019 from Department of Medicine, Shridevi Institute of Medical Sciences and Research Centre, Tumakuru.

A total of 100 caseswho gave consent to participate in the study was included through the inclusion and exclusion criteria mentioned below.

Inclusion criteria

1. Those admitted in shridevi institute of medical sciences and research hospital having fever of more than 1day duration.
2. Dengue NS 1antigen or IgM dengue positive.

\section{Exclusion criteria}

1. Age less than 14 years.

2. Other causes of thrombocytopenia like due to infections other than dengue, megaloblastic anaemia, cirrhosis etc.

3. Patients with history of haematological disorders. Written informed consent for the study was obtained from all of the patients aged 18 years or older or from the parents or guardians of the patients younger than 18 years.

Detailed clinical history, examination and required investigation were done for all patients.

Data was entered in Microsoft Office Excel Sheet 2010.

Definition used in the study ${ }^{7,8}$

Dengue fever

Fever is an acute febrile illness of 2-7 days duration (sometimes with two peaks) with two or more of the following manifestations:

- Headache

- Retro -orbital pain

- Myalgia/arthralgia

- Rash

- Leukopenia.

DHF: Dengue Haemorrhagic Fever is a probable case of dengue and haemorrhagic tendency evidenced by one or more of the following:

- Positive tourniquet test (A positive test is declared when $>20$ petechiae appear in a $2.5 \mathrm{~cm}$ square or $3 \mathrm{~cm}$ diameter circle on the skin surface on the forearm). In patients in shock, the test usually becomes positive if it is performed after the recovery from shock. The test may be negative or mildly positive ( $>10$ petechiae $/ 2.5 \mathrm{sq} \mathrm{cm}$ ) during the phase of profound shock.

- Petechiae, ecchymosis or purpura

- Bleeding from mucosa (mostly epistaxis or bleeding from gums), injection sites or other sites

- Haematemesis or melena

- Thrombocytopenia (platelets $100,000 /$ cu.mm or less) and

- Evidence of plasma leakage due to increased capillary permeability manifested by one or more of the following:

$>20 \%$ rise in haemotocrit for age and sex

$>20 \%$ drop in haemotocrit following treatment with fluids as

compared to baseline

Signs of plasma leakage (pleural effusion, ascites or

hypoproteinaemia).

DSS(Dengue shock syndrome ): Some patients of DHF manifest signs of restlessness, abdominal pain, and shock 
(rapid andweak pulse, cold clammy extremities, diaphoresis,circumoral cyanosis, irritability or change in mentalstatus). These cases known as DSS, are characterised by narrowing of the pulse pressure to $20 \mathrm{~mm}$ $\mathrm{Hg}$ or hypotension and in severe cases undetectable BP and pulse.
Thus, diagnosis of DSS is based on all the criteria of DHF plus manifestations of shock.

Ethical approval taken from Institutional Ethical Committee.

Table A : Grading of severity of dengue fever. ${ }^{9}$

\begin{tabular}{|c|c|c|c|}
\hline DF/DHF & Grade* & Symptoms & Laboratory \\
\hline DF & & $\begin{array}{c}\text { Fever with two or more of be following: } \\
\text { 1.Headache } \\
\text { 2.Retro-orbital pain } \\
\text { 3. Myalgia } \\
\text { 4. Arthralgia }\end{array}$ & $\begin{array}{c}\text { Leucopenia,occasionally } \\
\text { thrombocytopenia may be present, } \\
\text { no e/o plasma loss }\end{array}$ \\
\hline DHF & 1 & Above signs + positive tourniquet test & $\begin{array}{l}\text { Thrombocytopenia } \\
\quad<100,000 \\
\text { Hematocrit rise } \geq 20 \%\end{array}$ \\
\hline DHF & II & Above signs + spontaneous bleeding & - do - \\
\hline $\mathrm{DHF}$ & III & $\begin{array}{c}\text { Above signs + circulatory failure } \\
\text { (weak pulse, hypotension, restlessness) }\end{array}$ & - do - \\
\hline DHF & IV & Profound shock with undetectable BP and Pulse & - do - \\
\hline
\end{tabular}

*DHF Grade III and IV are also called as DSS.

\section{RESULTS}

In our study a total of 100 patients were studied and all patients undergone dengue serology testing. Dengue NS1antigen positive in $37 \%$ patients, IgM Dengue positive in $27 \%$ patients, NS1 and IgM Dengue positive in 20\% patients, NS1 and IgG positive in $4 \%$, IgM and IgG Dengue positive in 3\% patients. All three tests(NS1, IgM and IgG) positive in $9 \%$ patients (table no.1).

Table 1: Dengue serology report of patients

\begin{tabular}{ccc}
\hline Dengue serology & $\begin{array}{c}\text { No. of } \\
\text { patients }\end{array}$ & percent of patients \\
\hline NS1 antigen & 37 & $37 \%$ \\
IgM Dengue & 27 & $27 \%$ \\
NS1 antigen+ IgM Dengue & 20 & $20 \%$ \\
NS1 antigen+IgG Dengue & 4 & $4 \%$ \\
IgM Dengue + IgG Dengue & 3 & $3 \%$ \\
NS1 antigen+ IgM Dengue + IgG Dengue & 9 & $9 \%$ \\
\hline Total & 100 & $100 \%$ \\
\hline
\end{tabular}

In our study, age and gender distribution shows majority of the patients age is between 21 to $40 y e a r s$. Its about $49 \%$ among them $63 \%$ are male and rest $37 \%$ were female. $28 \%$ of patients are in age group between 41 to 60 years among them $68 \%$ are female and $32 \%$ were male, $19 \%$ of patients are in less than 20 years of age among them $74 \%$ male and rest $26 \%$ were female. $4 \%$ of patients belong to more 61 years of age among them both male and female shares $50 \%$ each(table no 2 ).

Table 2: Age and Gender distribution of patients

\begin{tabular}{|c|c|c|c|c|}
\hline \multirow{2}{*}{$\begin{array}{l}\text { Age in } \\
\text { years }\end{array}$} & \multicolumn{2}{|c|}{ Gender } & \multirow[t]{2}{*}{ No of patients } & \multirow{2}{*}{$\begin{array}{c}\text { Percent } \\
\text { of patients }\end{array}$} \\
\hline & Male & Female & & \\
\hline$<20$ & 14 & 5 & 19 & $19 \%$ \\
\hline $21-40$ & 31 & 18 & 49 & $49 \%$ \\
\hline $41-60$ & 9 & 19 & 28 & $28 \%$ \\
\hline$>61$ & 2 & 2 & 4 & $4 \%$ \\
\hline Total & 56 & 44 & 100 & $100 \%$ \\
\hline
\end{tabular}

In our study patients fever is present in $100 \%$ of cases. Headache present in $68 \%$ of patients, like wise myalgia in $72 \%$ of patients, joint pain in $43 \%$ of cases, vomiting in $31 \%$ of patients, pain abdomen in $33 \%$ of patients, generalised weakness in $81 \%$ of patients, cough in $11 \%$ of patients, itching in $14 \%$ of patients and viral rash present in $20 \%$ of patients. Bleeding 
manifestation seen in $23 \%$ of patients, pedal edema in $9 \%$ of patients, ascites in $28 \%$ of patients, pleural effusion in $3 \%$ of patients, hepatomeghaly seen in $18 \%$ of patients and signs of shock in $8 \%$ of cases(table no 3 ).

\begin{tabular}{|c|c|c|c|c|}
\hline \multirow{2}{*}{$\begin{array}{l}\text { Symptoms } \\
\text { And Signs }\end{array}$} & \multicolumn{2}{|c|}{ Present } & \multicolumn{2}{|c|}{ Absent } \\
\hline & No of patients & Percent of patients & No of patients & Percent of patients \\
\hline Fever & 100 & $100 \%$ & 0 & $0 \%$ \\
\hline Headache & 68 & $68 \%$ & 32 & $32 \%$ \\
\hline Myalgia & 72 & $72 \%$ & 28 & $28 \%$ \\
\hline Joint pain & 43 & $43 \%$ & 57 & $57 \%$ \\
\hline Vomiting & 31 & $31 \%$ & 69 & $69 \%$ \\
\hline Pain abdomen & 33 & $33 \%$ & 67 & $67 \%$ \\
\hline Generalised weakness & 81 & $81 \%$ & 19 & $19 \%$ \\
\hline Cough & 11 & $11 \%$ & 89 & $89 \%$ \\
\hline Itching & 14 & $14 \%$ & 86 & $86 \%$ \\
\hline Rash & 20 & $20 \%$ & 80 & $80 \%$ \\
\hline Bleeding manifestation & 23 & $23 \%$ & 77 & $77 \%$ \\
\hline Pedal edema & 9 & $9 \%$ & 91 & $91 \%$ \\
\hline Ascites & 28 & $28 \%$ & 72 & $72 \%$ \\
\hline Pleural effusion & 3 & $3 \%$ & 97 & $97 \%$ \\
\hline Hepatomeghaly & 18 & $18 \%$ & 82 & $82 \%$ \\
\hline Shock & 8 & $8 \%$ & 92 & $92 \%$ \\
\hline
\end{tabular}

In our study, bradycardia was documented in $39 \%$ of cases, tachycardia in $2 \%$ of cases and normal pulse rate in $59 \%$ of cases (table no 4).

Table 4: Pulse rate among patients

\begin{tabular}{ccc}
\hline Pulse rate $(\mathrm{bpm})$ & No. of patients & Percent of patients \\
\hline$<60$ & 39 & $39 \%$ \\
$61-100$ & 59 & $59 \%$ \\
$>101$ & 2 & $2 \%$ \\
\hline Total & 100 & $100 \%$ \\
\hline
\end{tabular}

In our study, leucopenia was seen in $53 \%$ of cases followed by normal total leucocytes in $42 \%$ and remaining $9 \%$ hadleucocytosis(table no 5).

Table 5: Total leucocyte counts among patients

\begin{tabular}{ccc}
\hline Total leucocyte counts & No.of patients & Percent of patients \\
\hline$<4000$ & 53 & $53 \%$ \\
4000 to 11000 & 42 & $53 \%$ \\
$>11000$ & 9 & $9 \%$ \\
\hline Total & 100 & $100 \%$ \\
\hline
\end{tabular}

In our study, thrombocytopenia of less than 1lakh was found in $74 \%$ of patients and platelet count of more than 1 lakh was found in $26 \%$ of cases(table no 6 ).

Table 6: Platelet counts among patients

\begin{tabular}{ccc}
\hline Platelet count & No.of patients & Percent of patients \\
\hline$<1$ lakh & 74 & $74 \%$ \\
$>1$ lakh & 26 & $26 \%$ \\
\hline Total & 100 & $100 \%$ \\
\hline
\end{tabular}

In our study, haematocrit of less than 40 was found in $44 \%$ of patients, haematocrit of 40.1 to 45 was found in $36 \%$ and haematocrit of more than 45.1 was found in $20 \%$ of cases(table no 7 ).

Table 7: Haematocrit among patients

\begin{tabular}{ccc}
\hline Haematocrit & No. of patients & Percent of patients \\
\hline$<40$ & 44 & $44 \%$ \\
40.1 to 45 & 36 & $36 \%$ \\
$>45.1$ & 20 & $20 \%$ \\
\hline Total & 100 & $100 \%$ \\
\hline
\end{tabular}


In our study, DF was diagnosed in $69 \%$ of cases followed by DHF diagnosed in $23 \%$ of cases and DSS in $8 \%$ of cases (table no 8).

Table 8: Spectrum of dengue illness among patients

\begin{tabular}{ccc}
\hline Spectrum of dengue illness & No. of patients & Percent of patients \\
\hline Dengue fever(DF) & 69 & $69 \%$ \\
Dengue haemorrhagic fever(DHF) & 23 & $23 \%$ \\
Dengue shock syndrome(DSS) & 8 & $8 \%$ \\
\hline Total & 100 & $100 \%$ \\
\hline
\end{tabular}

\section{DISCUSSION}

In this study, a total of 100 patients were admitted with fever and they were evaluated and studied for dengue NS1antigen and IgM dengue antibody positivity. In this study, confirmation of dengue by serology shows, NS1antigen positive in $37 \%$ patients, as compared to Patta Apparao et al.. ${ }^{10} \mathrm{NS} 1$ antigen positive in $50.3 \%$ and study done by Vidyadhara Rani P et al.. ${ }^{11} \mathrm{NS} 1$ antigen positive in $63 \%$. In this study, IgM Dengue was positive in 27 $\%$ patients,NS1 and IgM Dengue was positive in $20 \%$ patients, as compared to study by Patta Apparao et al.. ${ }^{10}$ IgM positive in $14.4 \%, \mathrm{NS} 1$ and IgM in $25.2 \%$ and study done by Vidyadhara Rani $\mathrm{P}$ et al.. ${ }^{11}$ IgM positive in $6 \%$,NS1 and IgM positive in 5\%. In this study on dengue, age distribution shows majority of the patients are of age group of 21 to 40 years its about $49 \%, 28 \%$ of patients are of age group between 41 to 60 years, $19 \%$ of patients are in less than 20years. Study done by Shekar EC et al.. ${ }^{12}$ is almost comparable with our study, $47 \%$ cases belong to 21 40 years, $32 \%$ belong to $>40$ years and $21 \%$ belong to 13 20 years group, as compared to study done by Vidyadhara Rani P et al.. ${ }^{11}$ where majority of cases $43.52 \%$ cases were in the age group of $15-30$ years, $20.5 \%$ belonged to 31 to
50 years of age and $6.64 \%$ cases belonged to above 50 years of age group.

In our study, gender distribution shows $56 \%$ males and $44 \%$ females, as compared to study by Shekar EC et al.. ${ }^{12}$ where $53 \%$ were males and $47 \%$ were females and study done by Vidyadhara Rani P et al.. ${ }^{11}$ where $61.46 \%$ were males and $38.53 \%$ were females.

In our study, all of patients presented with fever(100\%) followed by generalised weakness $81 \%$. Myalgia in $72 \%$, headache in $68 \%$ and multiple joint pain in $43 \%$ of patients, as compared with other studies done by Shekar EC et al.. ${ }^{12}$, Pradnya Mukund Diggikar et al.. ${ }^{13}$ and Vijay Sagar et al. ${ }^{14}$ where fever present all $100 \%$ of patients. Study done Shekar EC et al.. ${ }^{12}$ documented common symptom as myalgia (71\%) followed by joint pain $(65 \%)$, headache (61\%),pain abdomen(56\%) and simultaneously documented signs of bleeding manifestation in $21 \%$ and shock in $9 \%$ of cases. Study done by Pradnya Mukund Diggikar et al. ${ }^{13}$ documented myalgia in $80 \%$ of patients, joint pain in $46 \%$ and bleeding manifestation in $10 \%$ of patients. Study done by Vijay Sagar et al. ${ }^{14}$ documented headache in $70 \%$, joint pain in $66 \%$, myalgia in $37 \%$ of cases and bleeding manifestation in $15 \%$ of cases.

Table 9

\begin{tabular}{ccccc}
\hline $\begin{array}{c}\text { Symptoms } \\
\text { and }\end{array}$ & \multicolumn{4}{c}{ Percent of patients(\%) } \\
\cline { 2 - 5 } Signs & $\begin{array}{c}\text { Present } \\
\text { study }\end{array}$ & $\begin{array}{c}\text { Shekar EC et } \\
\text { al. }{ }^{12}\end{array}$ & $\begin{array}{c}\text { PradnyaMukund } \\
\text { Diggikar } \text { et al. }{ }^{13}\end{array}$ & Vijay Sagar et al. ${ }^{14}$ \\
Fever & 100 & 100 & 100 & 100 \\
Headache & 68 & 61 & 20 & 70 \\
Myalgia & 72 & 71 & 80 & 37 \\
Joint pain & 43 & 65 & 46 & 66 \\
Vomiting & 31 & 48 & 22 & - \\
Pain abdomen & 33 & 56 & 10 & - \\
Generalised weakness & 81 & - & - & - \\
Cough & 11 & - & - & - \\
Itching & 14 & - & - & 21 \\
Rash & 20 & 40 & 22 & - \\
Bleeding manifestation & 23 & 21 & 10 & - \\
Pedal edema & 9 & 8 & - & - \\
Ascites & 28 & 15 & - & 6 \\
Pleural effusion & 3 & - & - & - \\
Hepatomeghaly & 18 & 4 & - & - \\
Shock & 8 & 9 & - & - \\
\hline
\end{tabular}


In this study, pulse rate documentation demonstrates bradycardia in $39 \%$ of the cases as compared to study done by Yadav RK et al. ${ }^{15}$ where showed sinus bradycardia in $60 \%$ of cases and study done by Ramesh S et al. ${ }^{16}$ showed bradycardia in $27 \%$ of cases. In this study, leucopeniais seen in $53 \%$ of cases which is almost comparable with study done by Butt $\mathrm{N}$ et al.. ${ }^{17}$ where shows $52.8 \%$. Whereas the study done by Shekar EC et al. ${ }^{12}$ showed Leucopeniaonly in $18 \%$ cases. In this study, thrombocytopenia of less than 1lakh is found in $74 \%$ of patients meeting the WHO criteria i.e $<1$ lakh cells / cumm which is almost comparable with the study by Pradnya Mukund Diggikar et al. ${ }^{13}$ which shows $78 \%$ and study done by Vidyadhara Rani P et al. ${ }^{11}$ which shows $73.02 \%$ cases of thrombocytopenia. But study done by Vijay Sagaret al. ${ }^{14}$ observed only $15 \%$ of cases with thrombocytopenia. In the present study, DF is the most common type seen in $69 \%$ followed by DHF in $23 \%$ and DSS in $8 \%$ of cases. Study by Pradnya Mukund Diggikar et al. ${ }^{13}$ observed $76 \%$ of DF, $12 \%$ of DSS, $10 \%$ had DHF. Study by Shekar EC et al. ${ }^{12}$ shows DF in $81 \%$, DHF in $10 \%$ and DSS in $9 \%$ of cases. Study by Vijay Sagar et al. ${ }^{14}$ observed DF in $79 \%$, DHF in $17 \%$ and DSS in $4 \%$ of cases.

\section{CONCLUSION}

Dengue fever is the one of the most common important arboviral infections. It has become a one of the major public health problem. in India where cyclic epidemics are becoming more frequent. Spectrum of dengue illness varies from non severe to more severe form of dengue(DHF and DSS). Majority of cases are still DF, requires only supportive management and do not require platelet transfusion. So most of the cases should be managed at the local hospital without reffering to higher centre, so as to reduce cost burden on patients. Early recognition of warning signs and meticulous management can reduce the morbidity and mortality of dengue.

\section{REFERENCES}

1. www.who.int/southeastasia/news/speeches/symposium on dengue prevention and control September 2014.

2. DENGUE .Guidelines for diagnosis, treatment, prevention and control, 2nd Edition, World Health Organization, Geneva 2009; 1-144.

3. National vector borne disease .Available at:https://www.karnataka.gov.in/hfw/nhm/pages/ndcp_cd nvbdcp.aspx. Accessed on 21 December 2017.

4. Ramos MM, Tomashek KM, Arguello DF, et al... Early clinical features of dengue infection in Puerto Rico. Trans R Soc Trop Med Hyg 2009;103(9):878-84.
5. Chuang YC, Lin YS, Liu CC, et al... Factors contributing to the disturbance of coagulation and fibrinolysis in dengue virus infection. $\mathrm{J}$ Formos Med Assoc 2013;112(1):12-7.

6. Gupta E, Dar L, Kapoor G, et al... The changing epidemiology of dengue in Delhi, India.Virol J 2006;3:92.

7. Park K. Epidemiology of Communicable Diseases:Dengue syndrome. In: Park's textbook of Preventive and Social Medicine. 20th ed. Jabalpur, India: M/sBhanarsidasBhanot 2009: 218-22.

8. Goel.A, Patel DN, Lakhani KK, Agarwal SB, Aarwal A, Singla $\mathrm{S}$ et al...Dengue fever- A dangerous foe. J Indian AcadClin Med 2004; 5; 3:247-58.

9. WHO/SEARO. Guidelines for treatment of dengue fever/ dengue hemorrhagic fever in small hospitals, New Delhi. 1999.

10. PattaApparao, D.K.V. Prasad and Lavanya, S.V. 2018.Seasonal, Serological Markers and Platelet Count Association with Dengue Fever.Int.J.Curr.Microbiol.App.Sci. 7(10): 2513-2517.

11. Vidyadhara Rani P, Naveen Kumar S. Evaluation of thrombocytopenia in dengue infection along with seasonal variation. IAIM, 2018; 5(2): 57-63.

12. Shekar EC, Laxminarayana, Kishan B, Kumar S, Rao B. A prospective study to analyze the clinical, biochemical and hematological parameters of dengue fever in Mahatma Gandhi Memorial Hospital, Warangal, Telangana, India.Int J Adv Med 2017;4:218-24.

13. PradnyaMukundDiggikar, Prasanna Kumar Satpathy, Gaurav Dinesh Bachhav, Kanishka Dinesh Jain, AnujaMukeshPatil, PrafullChajjed. Study of clinical profile and complications of dengue fever in tertiary care hospital of pune city.NJMR;Volume 6;Issue I;Jan - Mar 2016:84-86

14. Vijay Sagar, Rashmi Singh, Ratnesh Kumar. ClinicalHematological Profile of Patient with Dengue Infection in Bihar: A Prospective Study. Int.J.sci. res. volume-6 | issue5 | may - 2017 | issn no 2277 - 8179 | if : 4.176 | ic value : 78.46

15. Yadav RK, Kumar S. To study cardiac manifestations in patients presenting with dengue infection and to find out the correlation of cardiac manifestations to warning signs of dengue. Int J Adv Med 2017;4:323-8.

16. Ramesh S, Basavaraju M, Sandeep R, Sharma, Shetty shivakumar, Srinivasa M, Surakshith T. K, Ravichethan Kumar. "Study of Bradycardia in Dengue Fever". Journal of Evolution of Medical and dental sciences 2014;vol.3,Issue 09, March 3;Page:23782388,DOI:10.14260/jemds/2014/2148.

17. Butt N, Abbassi A, Munir SM, Ahmad SM, Sheikh QH. Haematological and biochemical indicators for early diagnosis of dengue viral infections. J College Physicians Surg. 2008;18:282-5.

\section{Source of Support: None Declared Conflict of Interest: None Declared}

Policy for Articles with Open Access:

Authors who publish with MedPulse International Journal of Medicine, Print ISSN: 2550-7583, Online ISSN: 2636-4751 agree to the following terms: Authors retain copyright and grant the journal right of first publication with the work simultaneously licensed under a Creative Commons Attribution License that allows others to share the work with an acknowledgement of the work's authorship and initial publication in this journal.

Authors are permitted and encouraged to post links to their work online (e.g., in institutional repositories or on their website) prior to and during the submission process, as it can lead to productive exchanges, as well as earlier and greater citation of published work. 